\title{
Women with comorbid substance dependence and psychiatric disorders in Sweden: a longitudinal study of hospital care utilization and costs
}

Tina M. Olsson ${ }^{1 *}$ and Mats Fridell ${ }^{2}$

\begin{abstract}
Background: Substance use disorders are regarded as one of the most prevalent, deadly and costly of health problems. Research has consistently found that the prevalence of other psychiatric disorders among those with substance related disorders is substantial. Combined, these disorders lead to considerable disability and health years lost worldwide as well as extraordinary societal costs. Relatively little of the literature on substance dependence and its impact on healthcare utilization and associated costs has focused specifically on chronic drug users, adolescents or women. In addition, the research that has been conducted relies largely on self-reported data and does not provide long-term estimates of hospital care utilization. The purpose of this study is to describe the long-term (24-32 year) healthcare utilization and it's associated costs for a nationally representative cohort of chronic substance abusing women (adults and adolescents) remanded to compulsory care between 1997-2000 (index episode). As such, this is the first study investigating healthcare costs for women in compulsory treatment in Sweden.
\end{abstract}

Methods: Women $(n=227)$ remanded to compulsory care for substance abuse were assessed at intake and their hospital care utilization was retrieved 5-years post compulsory care from national records. Unit costs for ICD-10 diagnoses were applied to all hospital care used from 1975-2006. Attempts are made to estimate productivity losses associated with hospitalization and premature death.

Results: Upon clinical assessment it was found that a majority of these women had a comorbid psychiatric disorder (primarily personality disorder). The women followed in this study were admitted to hospital five to six times that of the general population and had stays six to eight times that of the general population. Total direct healthcare costs per person over the study period averaged approximately $\$ 173,000$ and was primarily the result of psychiatric department visits (71 \%) and inpatient treatment (98.5\%; detoxification and short-term rehabilitation).

Conclusions: Women placed in compulsory care use more hospital resources than that of the general Swedish population and when compared to international research of hospital care use and substance abuse. Direct hospital costs vary greatly over the life course. Effective services can have significant economic benefit.

Keywords: Cost of illness, Program evaluation, Treatment, Prevention, Intervention, Policy, Co-morbidity

\footnotetext{
*Correspondence: tina.marie.olsson@gmail.com

'Department of Social Work, Lund University, 22000 Lund, Sweden

Full list of author information is available at the end of the article
}

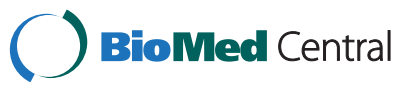

(c) 2015 Olsson and Fridell; licensee BioMed Central. This is an Open Access article distributed under the terms of the Creative Commons Attribution License (http://creativecommons.org/licenses/by/4.0), which permits unrestricted use, distribution, and reproduction in any medium, provided the original work is properly credited. The Creative Commons Public Domain Dedication waiver (http://creativecommons.org/publicdomain/zero/1.0/) applies to the data made available in this article, unless otherwise stated. 


\section{Background}

Substance abuse and dependence is one of the most prevalent, deadly, and costly of health problems [1-4] and is a component cause of more than 200 diseases in individuals leading to increased morbidity and mortality $[1,5-8]$. In the United States, the economic cost of drug abuse has been estimated at $\$ 180.9$ billion (2002 values; [9]) and the combined cost of alcohol and drug abuse has been estimated at $\$ 246$ billion (1992 values) [10]. In Sweden, substance abuse costs society an estimated 2.65 billion US dollars (2008 values) [11].

Clinical, epidemiological and general population studies have found that comorbid substance use and psychiatric disorders are common in the general population and even more prevalent among treatment populations [12-15]. In Sweden, it is estimated that among substance abusing patients between 30 and $50 \%$ suffer from a psychiatric disorder [11]. Mental illnesses [16], which include substance use and psychiatric disorders, are the leading causes of disability adjusted life years (DALYs) worldwide, accounting for $37 \%$ of health years lost from non-communicable diseases [16]. In addition, mental and substance use disorders [2] were found to be the leading cause of years lived with disability worldwide with depression, substance use disorders, and anxiety accounting for $75 \%$ of this burden [2]. Mental illness [17], including substance use disorders, rank in the top five of major non-communicable diseases worldwide with an estimated global cost to society at nearly $\$ 2.5$ trillion - higher than that of cancer, cardiovascular disease, chronic respiratory diseases and diabetes - and a cost projected to surge to $\$ 6.0$ trillion by 2030 [17].

Healthcare costs, along with crime costs and productivity losses, are consistently identified in international research as one of the largest contributors to the economic costs of substance abuse $[9,10,18-22]$. Despite the large economic burden to society of substance use and dependence as estimated by cost-of-illness studies, few studies have investigated the role of substance dependence in healthcare utilization or its associated cost. The growing literature suggests that substance use and dependence is positively and significantly related to health services utilization - such as hospital admissions and emergency room care - and cost [23-30]. Additionally, having a comorbid psychiatric disorder appears to increase the utilization and cost of healthcare services among patients with a primary diagnosis of substance use disorder [31].

Although the literature on substance dependence (and services) and its impact on healthcare utilization and associated costs continues to develop, relatively little of this research has focused specifically on chronic drug users [25], adolescents [32, 33], or women [29, 34]. In addition, longitudinal studies commonly have short ( $\leq 1$ year) time frames and often rely on self-reported healthcare use data. Importantly, few studies formally assess the extent to which participants have a substance dependence diagnosis or a co-morbid psychiatric disorder (ICD; DSMIV). Although exceptions to these identified limitations do exist [35-37], commentators interested in the future of research on substance abuse services have called for economic studies that focus on for example special populations of substance abusers [37]. These populations include for example women, adolescents and individuals with co-morbid disorders and which present long-term data [38].

Epidemiological data that describes healthcare utilization and costs over time for specific populations is valuable from a policy perspective as understanding trends in resource use can aid policy makers in decisions regarding how to target, deliver and improve services, as well as in understanding the potential benefits of effective intervention for specific groups of substance dependent individuals at specific points in time. Accurate empirical information could also help researchers in developing alternative models and formulating research initiatives. In addition, data regarding the longitudinal patterns of healthcare utilization and cost is of potential interest to researchers investigating the clinical outcomes of treatment services (such as reductions in healthcare utilization), as the majority of outcome studies do not include an economic arm [22, 39].

As such, the purpose of this study is to describe the long-term (24-32 years) pattern of healthcare utilization and its associated costs for a nationally representative cohort of chronic substance abusing women (adults and adolescents). These women were placed in compulsory care between 1997-2000 (index episode) as a result of their chronic substance abuse. Compulsory care in Sweden occurs when individuals are remanded to treatment, in an institutional setting, by the court even though he or she has not committed any crime. Although these women were originally identified, remanded to care and included in the cohort due to their substance use disorder, subsequent research [40-42] has found that $80 \%$ of the patients had a comorbid substance dependence and psychiatric disorder (primarily personality disorder). Importantly, this is not a group of dual diagnosis patients [43]. That is, this group is not one characterized by severe mental illness but instead, is one of chronic substance abusing women with severe social problems, personality disorders, ADHD and persistent criminal behavior.

This study aims to answer the following questions:

(1)What is the degree of resource use (number of hospitalizations and length of stay) by type of service among women remanded to compulsory care? 
(2) What is the total average direct cost of hospital care received by women remanded to compulsory care over the study period?

(3) What is the value of lost productivity due to hospitalization and premature death for women remanded to compulsory care?

(4) What is the potential benefit of preventing future hospitalizations among women remanded to compulsory care at a given age?

This study is the third in a series of economic studies describing this group. The first investigated the longterm pattern of criminal justice system involvement and costs [44] and the second investigated productivity losses associated with criminal behavior [45]. This study builds on these prior investigations by describing the group's use of direct healthcare resources and associated productivity losses.

\section{Method \\ Subjects}

All patients admitted to Lunden from January 1, 1997 to December 31, $2000(n=227)$ were consecutively included in the cohort followed in this study. At the time of this study, Lunden was a 21-bed inpatient compulsory care residential treatment unit run by the National Board of Institutional Care (SiS). Lunden was one of $36 \mathrm{SiS}$ run facilities nationwide with a national catchment area. The treatment unit was reserved for the treatment of women exclusively, with a focus on drug addiction. The unit staff included psychologists, psychiatrists, nurses, social workers, treatment attendants, and administration [46-48]. The institution had 9 beds for youth (LVU) and 12 beds for adults (LVM). In the Lunden cohort, 92 women (40.5\%), were remanded to LVU care and 135 (59.5\%) to LVM care. Thus, within the Lunden cohort, there are two distinct subgroups of patients (LVU and LVM).

A psychosocial assessment (SCID-II; DSM-IV) [49] was administered to all women at admittance and all participants met the diagnostic criteria for substance (narcotic) dependence. Additionally, substance use was assessed via supervised urine samples throughout index care episode and analyzed by Gas chromatography mass spectrometry (GC-MS). The substances used by the cohort prior to admission included: stimulants, mainly amphetamine (51\%), opiates, mainly heroin (35\%), alcohol (7\%), or sedatives/other drugs (<3\%). Cannabis was used by $20 \%$ of the women in addition to other drugs [39-41]. This pattern of poly-substance use is common for clinical samples of narcotic drug abusers in Sweden [50].

The clinical assessment of psychiatric disorders was based on standardized diagnostic methods and psychological testing. It revealed that $78 \%$ of the women had at least one personality disorder according to DSM-IV,
SCID-II and $42 \%$ had at least one psychiatric disorder. Psychiatric disorders (axis I; ICD-10) identified in this group included: anxiety- and depressive disorders (36 \%), and psychoses (Schizophrenia $5 \%$ and substance related psychosis $15 \%$ ) [40-42]. About $60 \%$ of the patients had at least one prior serious suicide attempt.

The mean age of the subjects at intake to treatment was 18.7 years for the LVU subjects (range: $16-20$ ) and 26.7 for the LVM subjects (range: 18 - 43) [40,41]. Of the women followed in this study, $92.9 \%$ have been charged for at least one crime [44] and 22 died prior to five-year follow-up January 1, 2007 (4 LVU; 18 LVM) (9.7; $4.3 \%$ LVU; $13.3 \%$ LVM). In the cases of premature death, substance use was the primary cause of 18 deaths and somatic disease was the primary cause of four of the deaths. The causes of death were diagnosed by reviewing ICD-10 coding from autopsy protocols obtained from the forensic units in Sweden. In addition, death certificates were obtained from official records maintained by the National Board of Health and Welfare, Stockholm, Sweden and reviewed.

\section{The compulsory care system in Sweden}

The compulsory care system in Sweden is charged with treating (1) youth with serious psychosocial problems and (2) adult substance abusers. Youth are admitted to compulsory care under The Care of Young Persons Act (LVU, act 1990:52). According to the LVU, "A care order is to be issued, if the young person exposes his health or development to a palpable risk of injury through the abuse of addictive substances, criminal activities, or some other socially degrading behavior." (LVU, act 1990:52, section 3). Adult substance abusers are admitted to compulsory care under the Law on Compulsory Care for Substance Abusers (LVM, act 1988:870). Under Section 4 of the LVM, a court can order compulsory care for a person whose health is deemed to be at risk, or who may be placing others at risk, and who is considered to need assistance in order to discontinue substance use. The LVU and LVM acts are unrelated to penal code or laws of psychiatric care. Individuals exhibiting a need for compulsory care are primarily reported to the court by: social welfare, police, family members, psychiatrist, substance abuse treatment provider or, more rarely, a general practitioner. Within 8 days of the report, an assessment of need for treatment or physician evaluation must be completed, and court hearings proceed. For those remanded to compulsory care, care orders are implemented in specially certified LVU and LVM facilities that are run under the authority of the National Board for Institutional Care (SiS). The compulsory care system is separate and independent from the mainstream healthcare system in Sweden. The number of women undergoing compulsory care annually in Sweden is approximately 650 - 700 [51]. 


\section{Consent}

Written consent to participate in the present study was provided by all participants. Participation in the present study was voluntary and individual participants could drop out of the study at any time. Information was provided verbally and in written form to individuals prior to recruitment as well as prior to follow-up, five years post referral. Participants provided written consent at both of these time points.

\section{Economic analysis}

\section{Resource use}

The National Patient Register (NPR) maintained by the National Board of Health and Welfare, Stockholm, Sweden provides the basis for resource use measures. Data on healthcare resource utilization at the individual level is collected prospectively for all Swedish citizens and housed in the NPR. NPR data was accessed retrospectively, five-years post index care admission. Data spans the period 1975, when the NPR was introduced in Sweden through 2006, 5-years following the last index care admission. As individuals entered the study at varying ages, healthcare resource use was tracked for between 24 and 32 years depending on the age of the participant when they entered compulsory care. All in hospital outpatient physician visits and inpatient hospitalizations including length of stay and primary diagnosis (ICD) were included in the NPR for the period under review.

\section{International classification of diseases (ICD)}

During the period under review, primary diagnosis was coded in the NPR using three versions of the ICD: 1975 to 1986, ICD-8; 1987 to 1996 , ICD-9; and 1997 onward, ICD-10. In order to align the ICD coding with the unit cost coding, all codes were converted to ICD-10 equivalents or approximates using primarily three documents [52-54] and one on-line resource (www.icd10data.com). Conversion was made by manually comparing text from the diagnoses coded with ICD-8 and ICD-9 to the text of ICD-10 codes.

\section{Unit cost}

Unit cost estimates were applied at the individual level to all hospital visits. Costs per hospital visit were summed to arrive at a total cost per person.

\section{Cost Per Patient Database (KPP)}

Unit costs per ICD-10 primary diagnoses were taken from Sweden's Cost per Patient Database (KPP) maintained by the Swedish Association of Local Authorities and Regions $[55,56]$ and publicly available. The KPP provides nationwide estimates of unit costs within the hospital setting. These cost estimates are based on the costs of providing services and estimation is based on individual patient contacts with hospital care across Sweden. The KPP provides a nationwide estimate of the cost per visit based on ICD-10 diagnoses and includes main diagnosis and all subsequent diagnoses and is not adjusted for comorbidities. In this analysis, the 2010 unit (day) cost for the average woman receiving care by primary diagnosis was used to value hospital stays.

\section{Outpatient visits}

In most cases the cost per outpatient visit was not available. For all outpatient physician visits the daily rate of inpatient hospitalization by primary diagnosis is used as a proxy for the cost per outpatient physician visit.

\section{Productivity loss}

There are several methods available for estimating productivity loss $[57,58]$. In this study, productivity loss is measured using the human capital approach [59] and as such follows the methodology used in two prior studies of this group [44, 45]. This approach values productivity loss as the present value of lost time according to the market wage. Productivity loss due to hospital stays is valued using the average wage for women during 2010 of 26,200 SEK $(\$ 2,901)$ per month [60]. Lost life is valued using the present value of future earnings and estimated using the average monthly wage for women across Sweden by age (ibid).

\section{Currency, inflation and time preference}

Costs were calculated in Swedish crowns (SEK) and are reported in the text and tables in US dollars (2010). Unit costs were estimated for year 2010 and applied at the individual level to resource use. The purchasing power parity (PPP) based exchange rate in 2010 was $9.03 \mathrm{SEK}=$ 1.00 US Dollar $=0.76$ Euro [61] and was used to convert currency in this study. All currency conversions were conducted post-analysis.

In the primary analysis, no discounting is performed. However, discounting is performed in subsequent analyses order to show how effective prevention at various time points (ages) could impact direct healthcare cost outcome. Prior studies of this population have found that depending on substance of choice (i.e., alcohol, cocaine, heroin, etc.) and group (i.e., LVU, LVM), debut age for substance use occurred between the ages of 12 and 20. In addition, the women in the LVU group were placed in index care between the age of 17 and 19 while the women in the LVM group were placed in index care between the ages of 21 and 30 [40]. These age points are used as probable intervention points in order to estimate the present value of potential benefits of prevention activities. Additionally, discounting is performed in order to estimate the present value of productivity loss at (1) time of first hospitalization and (2) time of death. 


\section{Missing values}

In the original data set, 116 (2.4\%) entries either did not provide a primary diagnosis or the primary diagnosis code given did not correspond with a diagnosis code from ICD-8, ICD-9 or ICD-10. These entries were subsequently removed from the analysis.

\section{Statistical analysis}

All primary data is housed in Excel version 14.0.0 and all analyses in which discounting is performed were conduced in Excel. All other analyses were conducted using SPSS version 20. Descriptive statistics are presented for the entire sample (Lunden) as well as for the subgroups found within the sample (LVU, LVM) separately. Comparisons are not made between groups.

\section{Results}

\section{Hospital admissions}

During the period under review, women were admitted 4,737 times for inpatient hospitalizations (87.9\%), outpatient visits $(10.3 \%)$ or emergency care $(1.6 \%)$. Individuals were admitted most often, $41.8 \%$ for psychiatric department visits. These were followed by: somatic care other than reproductive health (ob/gyn) (29.4\%), alcohol/drug services (20.2 \%) and ob/gyn visits (8.3\%). The mean number of hospital visits per person over the study period was 20.87 (12.65, LVU; 26.47 LVM) (sd, 30.87 Lunden; 15.14 LVU; 37.06 LVM). Table 1 reports the average number of hospital admissions per person. Figure 1 shows the average number of hospital admissions per year at a given age over the life course.

\section{Length of stay}

The average number of days in care per person during the period under review was 172.01 (sd 437.98) for the Lunden cohort and 83.63 (sd 167.80) and 232.24 (sd
543.50) days for the LVU and LVM subgroups respectively. The average LOS per person per hospital admission was 8.24 (sd 35.64) for the cohort (LVU 6.61, sd 24.08; LVM 8.77, sd 38.65). Table 1 reports the average length of stay per person. Figure 1 shows the average number of days in care per year at a given age over the life course.

\section{Total costs}

Table 2 reports the average total direct hospital costs per person by clinic and admission type. Average total direct hospital costs per person were $\$ 173,048$ (\$82,857, LVU; $\$ 234,512$ LVM) (sd \$446,009 Lunden; \$166,911, LVU; $\$ 554,246$ LVM). Psychiatric department visits made up the majority of total costs $(70.8 \%)$. These were followed by: somatic care other than ob/gyn (13.2\%); alcohol/ drug services (12\%); and ob/gyn visits (3.8\%). Hospital costs were primarily the result of inpatient treatment $(98.5 \%)$. Figure 2 shows the average cost per person by age over the life course.

Table 3 summarizes the average value of lost productivity per person due to hospitalization and premature death. The average age of death for the 22 (4 LVU, 18 LVM) women that passed away prior to 2008 was 34.68 (sd 10.53) (LVU 21.25, sd 3.20; LVM 37.66, sd 9.13). Premature death accounted for the largest proportion of productivity losses.

Table 4 reports on the present value (direct hospital costs) of preventing hospitalizations at various time points in an individual's life.

\section{Discussion}

The purpose of this study was to describe the long-term (24-32 years) healthcare utilization and its associated costs for a nationally representative cohort of chronic substance abusing women in compulsory care. The participants in this study had on average over 20 hospital

Table 1 Resource use: average (standard deviation) number of hospital visits and length of stay (days) per person by primary service for the Lunden cohort and the LVU and LVM subgroups

\begin{tabular}{|c|c|c|c|c|c|c|}
\hline & \multicolumn{2}{|l|}{$\mathrm{LVU} n=92$} & \multicolumn{2}{|l|}{$\underline{\operatorname{LVM} n=135}$} & \multicolumn{2}{|l|}{ Lunden $n=227$} \\
\hline & $\begin{array}{l}\text { Mean (s.d.) } \\
\text { hospitalizations }\end{array}$ & $\begin{array}{l}\text { Mean (s.d.) } \\
\text { length of stay }\end{array}$ & $\begin{array}{l}\text { Mean (s.d.) } \\
\text { hospitalizations }\end{array}$ & $\begin{array}{l}\text { Mean (s.d.) } \\
\text { length of stay }\end{array}$ & $\begin{array}{l}\text { Mean (s.d.) } \\
\text { hospitalizations }\end{array}$ & $\begin{array}{l}\text { Mean (s.d.) } \\
\text { length of stay }\end{array}$ \\
\hline \multicolumn{7}{|l|}{ Clinic } \\
\hline Alcohol/drug services & $2.67(7.38)$ & $12.76(47.27)$ & $5.28(8.08)$ & $25.4(41.2)$ & $4.22(7.9)$ & $20.27(44.1)$ \\
\hline Psychiatric department & $4.01(6.68)$ & $52.46(142.48)$ & $11.96(24.64)$ & 171.56 (519.83) & $8.74(19.8)$ & $123.29(414.52)$ \\
\hline Reproductive health & $.96(1.56)$ & $3.1(6.43)$ & $2.29(3.51)$ & $9.2(16.52)$ & $1.75(2.95)$ & $6.73(13.69)$ \\
\hline Other Somatic & $4.98(6.33)$ & $15.29(33.47)$ & $6.93(10.21)$ & $26.08(41.74)$ & $6.14(8.88)$ & $21.70(38.89)$ \\
\hline \multicolumn{7}{|l|}{ Type of Admission } \\
\hline Inpatient & $10.86(13.17)$ & $83.50(167.70)$ & $23.44(32.91)$ & $231.74(543.22)$ & $18.34(27.39)$ & $171.66(437.73)$ \\
\hline Outpatient & $1.62(2.42)$ & - & $2.54(4.38)$ & - & $2.17(3.73)$ & - \\
\hline Emergency & $.14(.45)$ & - & $.47(1.12)$ & - & $.34(.92)$ & - \\
\hline Total & $12.65(15.14)$ & $83.63(167.80)$ & $26.47(37.06)$ & $232.24(543.50)$ & $20.87(30.87)$ & $172.01(437.98)$ \\
\hline
\end{tabular}




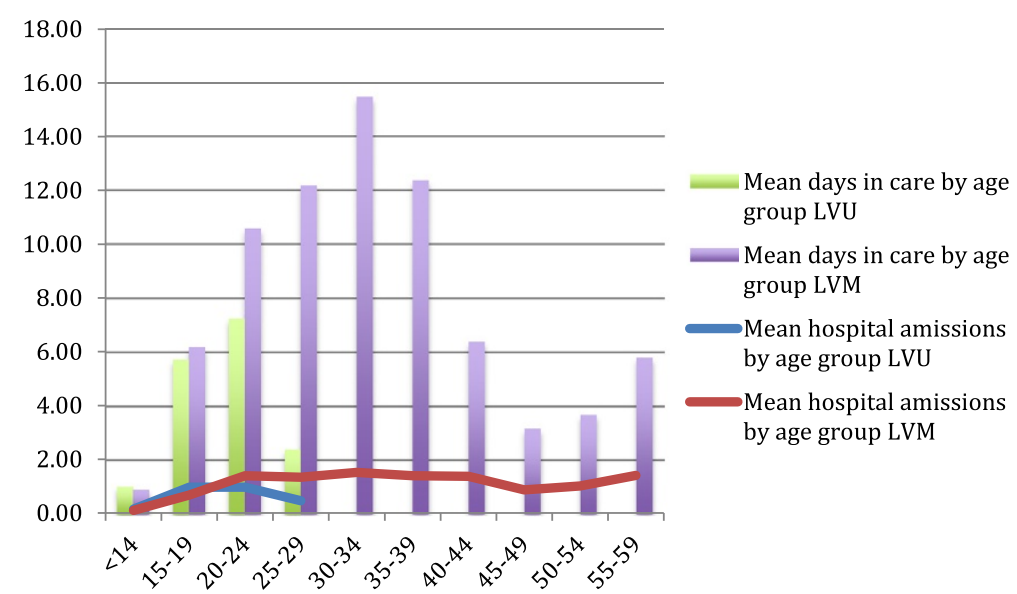

Fig. 1 Resource use: Mean number of hospital admissions and mean number of days in care per person per year by age group based on number of participants at age

admissions with total average days in care of 172 per person (Table 1) over the study period. This resource use varied greatly by group and age over the life course (Fig. 2). National figures [62] stemming from population based healthcare use report the average number of healthcare visits (including primary care) in 2010 to be approximately 15.4 per 100 . Depending on age, the participants in this study were admitted to hospital five to six times (65.2-86.9 admissions annually per 100) more than the general population. Similarly, the total number of days in care per person across the population in 2010 was reported at 88 per 100 [63]. Participants in this study averaged six to eight times (537-716 days annually per 100) the national average. These results indicate that women placed in compulsory care for substance abuse have a substantially higher rate of hospital admissions and extended length of stays compared to that of the general Swedish population.
Not only did the participants in the current study use more hospital care resources as measured by hospital admissions and length of stay but they also appear to use more resources when compared to international research on healthcare utilization and substance use. For example, in a nationally representative study on illicit drug use and health services utilization [23], female participants' (aged 18-60; substance using and non substance using) were hospitalized on average 0.131-0.171 times and visited the ER on average 0.373-0.429 times during the year. Estimation results for count measures of healthcare utilization revealed that heavy drug users had about a $30 \%$ higher rate of hospital admissions than non-drug users. Similarly, in a study undertaken by French and colleagues [25] which estimated the annual use of hospital care, chronic drug users and injection drug users (men and women) were admitted to hospital 0.31 and 0.32 times respectively. Further, outpatient

Table 2 Healthcare costs: average (standard deviation) total direct hospital care costs per person by primary service for the Lunden cohort and the LVU and LVM subgroups, USD 2010

\begin{tabular}{llll}
\hline & LVU $n=92$ mean (s.d.) cost (USD) & LVM $n=135$ mean (s.d.) cost (USD) & Lunden $n=227$ mean (s.d.) cost (USD) \\
\hline Clinic & & & \\
Alcohol/drug services & $14,341(68,866)$ & $25,387(43,822)$ & $20,911(55,478)$ \\
Psychiatric department & $50,012(129,941)$ & $127,791(529,944)$ & $122,612(420,622)$ \\
Reproductive health & $2,755(6,034$ & $9,224(16,445)$ & $6,602(13,607)$ \\
Other Somatic & $15,749(38,333)$ & $27,810(44,945)$ & $22,922(42,716)$ \\
Type of Admission & & & $170,541(443,179)$ \\
Inpatient & $81,209(165,568)$ & $231,419(550,841)$ & $2,085(3,689)$ \\
Outpatient & $1,474(2,394)$ & $2,501(4,316)$ & $422(1,280)$ \\
Emergency & $173(766)$ & $592(1,514)$ & $173,048(446,009)$ \\
Total & $82,857(166,911)$ & $234,512(554,246)$ & \\
\hline
\end{tabular}




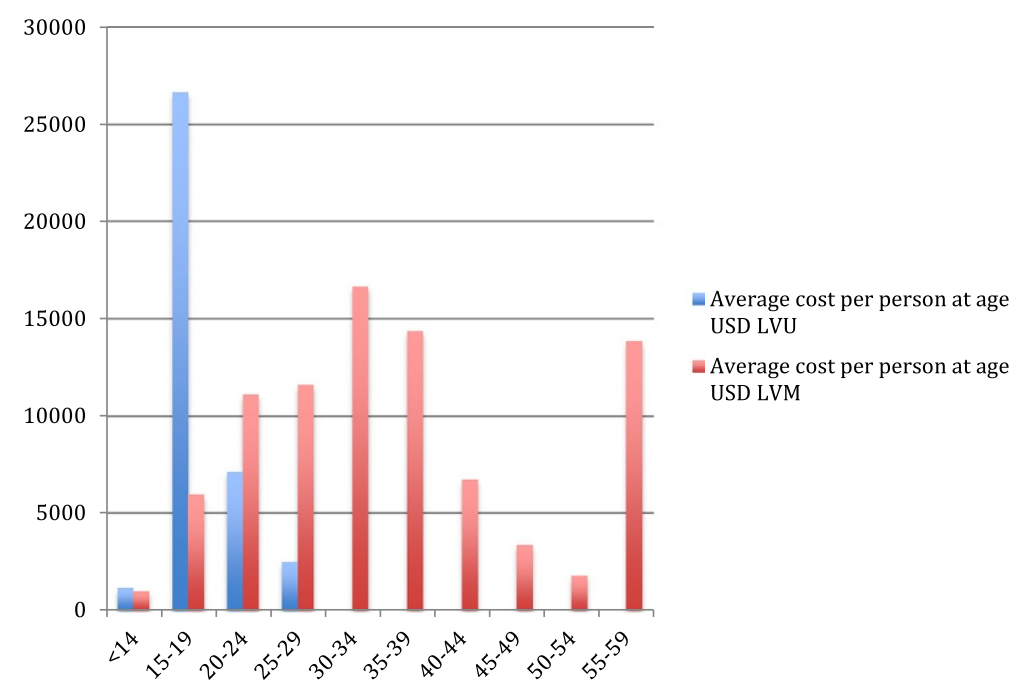

Fig. 2 Mean direct hospital care cost per person per year by age group based on number of participants at age

visits and emergency room episodes ranged from 1.231.42 and $0.78-0.79$ respectively for the two groups of drug users.

The inflated resource use as found in this study translated to hospital care costs for women remanded to compulsory care for substance use much higher than that of the general population. The average direct cost of hospital care per person was approximately $\$ 173,000$ over the study period (Table 2). The annual value of direct hospital care costs varied greatly depending on age and group (Fig. 2). National figures [64] place the average cost for healthcare (including primary care and pharmaceuticals) across the population at approximately $\$ 2,300$ per person in 2010 . The participants in this study had an estimated annual cost of hospital care between approximately two and three times this national average. Further, psychiatric care made up approximately $9 \%$ of the national average while in this study, psychiatric care

Table 3 Present value of lost productivity due to hospitalization and premature death for the Lunden cohort and the LVU and LVM subgroups USD, 2010

\begin{tabular}{|c|c|c|c|}
\hline & $\begin{array}{l}\text { LVU } n=92 \\
\text { Mean (s.d) cost (USD) }\end{array}$ & $\begin{array}{l}\text { LVM } n=135 \\
\text { Mean (s.d.) cost (USD) }\end{array}$ & $\begin{array}{l}\text { Lunden } n=227 \\
\text { Mean (s.d.) cost (USD) }\end{array}$ \\
\hline \multicolumn{4}{|c|}{ Hospitalization } \\
\hline $0 \%$ & $7,974(16,000)$ & $22,144(51,822)$ & $16,401(41,761)$ \\
\hline $3 \%$ & $6,412(13,196)$ & $15,751(35,991)$ & $11,966(29,313)$ \\
\hline $5 \%$ & $5,659(11,850)$ & $12,878(28,995)$ & $9,952(23,825)$ \\
\hline \multicolumn{4}{|c|}{ Premature death } \\
\hline $0 \%$ & $66,112(312,222)$ & $131,229(354,362)$ & $104,838(338,722)$ \\
\hline $3 \%$ & $36,702(173,103)$ & $88,568(232,333)$ & $67,547(211,475)$ \\
\hline $5 \%$ & $26,823(126,504)$ & $71,372(185,383)$ & $53,317(165,230)$ \\
\hline
\end{tabular}

accounted for approximately $71 \%$ of the total healthcare costs incurred by this group. Lost productivity due to hospitalization and premature death added substantially to this average cost and increased total cost estimates by $70 \%$.

It is clear that effective services for chronic substance abusing women can have significant economic benefits. A recent review which included twenty-four research reviews and forty-three research trials of evidence-based treatments for substance abusing patients with comorbid psychiatric disorders [63] found that the effectiveness of treatment varies by type (combination) of co-occurring disorder [65]. Further, depending on the nature of the diagnosis, stability in recovery may be contingent upon addressing the substance abuse early on while improvement of non-substance related disorders may precede improvement of substance use symptoms. Generally, treatment planning for patients with comorbid substance use and psychiatric disorders is more effective when effective therapeutic modalities (i.e., psychotherapy, pharmacotherapy and behavioral treatments) are combined [66, 67]. Unfortunately, none of the research reviewed assessed changes in patient hospitalization. Further research on the clinical outcomes of interventions for individuals with comorbid substance dependence and psychiatric disorders should attempt to incorporate resource use measures into assessment batteries [66].

It should be highlighted that a whole $10 \%$ of the women in this study died prematurely at the average age of 34.5 years, within five years of index care episode. This is much earlier than was found in two prior studies conducted on substance abusing women in Sweden, which found the average age of premature death to be 37.5 and 42 years $[7,67]$. 
Table 4 Present value of preventing future hospitalizations at given age for the Lunden cohort and the LVU and LVM subgroups, direct hospital costs, USD (2010)

\begin{tabular}{lllllll}
\hline & $\begin{array}{l}\text { LVU } n=92 \\
\text { mean (s.d.) cost (USD) }\end{array}$ & LVM $n=135$ & Lunden $n=227$ & LVU $n=92$ & LVM $n=135$ & Lunden $n=227$ \\
& mean (s.d.) cost (USD) & mean (s.d.) cost (USD) & mean (s.d.) cost (USD) & mean (s.d.) cost (USD) & mean (s.d.) cost (USD) \\
\hline Age & $3 \%$ Discount & & & $5 \%$ Discount & & \\
13 & 56,892 & 151,373 & 113,581 & 49,868 & 119,166 & 91,447 \\
14 & 57,616 & 153,617 & 115,217 & 51,357 & 122,783 & 94,213 \\
15 & 55,645 & 155,180 & 115,366 & 50,153 & 125,818 & 95,552 \\
16 & 54,946 & 115,472 & 115,650 & 50,247 & 128,320 & 97,091 \\
17 & 52,816 & 157,483 & 115,627 & 48,907 & 131,351 & 98,374 \\
18 & 46,087 & 159,310 & 114,021 & 42,878 & 98,131 \\
19 & 43,083 & 157,182 & 111,543 & 40,550 & 134,966 & 97,024 \\
21 & 33,676 & 147,688 & 102,086 & 32,263 & 134,673 & 90,188 \\
26 & 2,382 & 104,626 & 63,729 & 2,341 & 128,805 & 57,313 \\
27 & 1,405 & 98,268 & 59,523 & 1,389 & 93,960 & 53,942 \\
29 & - & 82,162 & 49,297 & - & 88,977 & 45,214 \\
30 & - & 74,736 & 44,842 & - & 69,356 & 41,425 \\
\hline
\end{tabular}

\section{Conclusions}

It is clear that women remanded to compulsory care for substance abuse are an extremely vulnerable group, even when compared to other populations of substance dependent individuals in Sweden and internationally. A majority of women remanded to compulsory care for substance abuse have comorbid psychiatric disorders with multi-problem profiles including a high rate of personality disorder. In addition, their use of hospital care as measured by episodes of hospitalization and length of stay is substantially higher than that of the general public. The healthcare system that can positively impact the extent, to which this population is hospitalized, especially in inpatient psychiatric care, can not only improve the lives of substance abusing women but can also improve the healthcare system. This represents an opportunity for policy makers within psychiatric and compulsory care to improve the health monitoring and treatment of patients with comorbid substance abuse and psychiatric disorders. The ability of the healthcare system as well as the compulsory care system to positively impact health outcomes for this group is pressing as a whole $10 \%$ of participants died prematurely - less than five years following compulsory care placement.

This study provides long-term individual based estimates of the potential benefit of effective prevention activities for reducing hospitalizations among women with comorbid substance use and psychiatric disorders. This gives policy makers an estimate by which to compare the costs and effects of intervention activities. For example, an intervention that targets this population at 16 years of age, costs $\$ 10,000$ per person and has the potential of preventing hospitalizations over a two-year period in
$10 \%$ of the individuals treated, may provide close to $\$ 10,000$ in net benefit (Table 4). In other words, when policy makers know the cost and potential effect of competing interventions, the estimates provided in this study can be used to estimate the potential healthcare benefit of these interventions. It is, however, necessary for studies investigating the effects of prevention and treatment activities to routinely assess the extent to which substance abusing women have a comorbid substance use and psychiatric disorder as well as track changes in economic variables such as criminal behavior, hospitalizations and employment patterns. This does not happen routinely in current research initiatives.

\section{Methodological considerations and study limitations}

The costing methodology used in this study has advantages over other approaches as it (1) followed a nationally representative sample of substance abusing women in compulsory care; (2) employed standardized diagnostic assessment instruments; (2) used actual resource use based on national records as opposed to self reports; and (3) used national unit cost estimates. Other unique aspects of this study include the assessment of longterm (24-32 years) costs and the inclusion of both adolescent and adult women. The breakdown of healthcare costs by age and inclusion of productivity losses facilitates the use of these estimates for a wide variety of research, evaluation and policy purposes. Still, several methodological issues should be highlighted.

First, outpatient physician visits in this study were valued using the average cost per day for hospitalization, as costs per outpatient physician visit were not available. This is likely an overestimate of the cost 
of outpatient care as hospital stays include for example hoteling, which is not part of the cost of outpatient care. The estimate produced, however, accounted for a small portion $(1.2 \%)$ of the direct healthcare costs estimated in this study. Further, the average cost per outpatient physician visit in this study was valued at approximately $\$ 997$ per visit. This falls within the estimate of $\$ 111$ - 2,879 (2001 values) per outpatient physician visit found in a prior study of costs within the hospital setting [68].

Second, the cost of primary care was not valued in this study. This data is not routinely reported in Swedish registers and was therefore not available for this study. However, this group of patients in general is not treatment seeking and the individuals are chronic non-compliers; hence, when appointments are made, they are often missed. For the purposes of this study, therefore, the cost of primary care for this group may be negligible.

Third, in this study, pharmaceutical use was not valued. Although estimates are available for pharmaceutical \#use among the general (female) population [69, 70] and among patients in outpatient psychiatric care [71] in Sweden, no estimates are available for pharmaceutical use among chronic substance abusers or among patients with co-occurring substance use disorders. As the clinical study upon which this study is based did not track pharmaceutical use we were unable to base this estimate on primary data and it is uncertain as to how accurate the above estimates are for this population.

Fourth, the cost of sick leave absence and presenteeism was not estimated in this study as access to primary data on sick leave for this sample was not available. Although estimates on sick-leave absence among the general population are available [72] it is uncertain how accurate these estimates are for this population.

Fifth, the cost of informal care was not included in this study. Informal care occurs when people, without payment, provide help and support to family members or friends who may not be able to manage without this help because of frailty, illness, or disability. Studies have shown that carers of persons with a severe mental illness or co-occurring disorder provide substantial support in terms of time spent providing care, involvement in crisis situations and monetary expenditures. For example, a study of families of individuals with a substance use disorder found that $89 \%$ of the families in the study provided informal care. On average, families in the study provided between 16.72 and $38.75 \mathrm{~h}$ of informal care during a two-week period [73]. Another study found that on average primary caregivers provided 73 more hours of care each year than non-primary caregivers [74]. The group of women followed in the present study, however, often lacked close relatives and therefore had few contacts with relatives or informal caregivers [40].

\section{Competing interests}

The authors declare that they have no competing interests.

\section{Authors' contributions}

TO was responsible for design, data collection, and data/statistical analysis for the current economic study. TO was the primary author of this report. MF designed the clinical study upon which this study is based. Primary data collection was completed as part of that study. TO and MF approved the final manuscript.

\section{Acknowledgements}

The authors would like to thank the members of the original research team J. Billsten, I. Jansson, M. Hesse without whom this study would not have been possible. This research was supported by the National Board for Institutional Care (SiS Grant \# 41-230-2010). This research has been approved by the Regional Ethical Review Board at the University of Lund, Lund, Sweden (LU 88-02; Dnr 287/2005).

The authors would also like to thank A. Nyhlen for evaluating patients' cause of death and her thoughtful comments on earlier versions of this manuscript.

\section{Ethics}

This research has been approved by the Regional Ethical Review Board at the University of Lund, Lund, Sweden (LU 88-02; Dnr 287/2005).

\section{Funding}

This research was supported by the National Board for Institutional Care (SiS; Grant \#41-230-2010) and provided indirectly through Linnaeus Unviersity, Växjö, Sweden.

\section{Author details}

${ }^{1}$ Department of Social Work, Lund University, 22000 Lund, Sweden. ${ }^{2}$ Department of Psychology, Lund University, 22000 Lund, Sweden.

Received: 28 December 2014 Accepted: 18 May 2015

Published online: 06 June 2015

\section{References}

1. World Health Organization: Global Status Report on Alcohol and Health. In. Geneva, Switzerland; 2014

2. Whiteford HA, Degenhardt L, Rehm J, Baxter AJ, Ferrari AJ, Erskine HE, et al. Global burden of disease attributable to mental and substance use disorders: findings from the global burden of disease study. Lancet. 2013;382(9904):1575-86.

3. Lynskey MT, Strang J. The global burden of drug use and mental disorders. Lancet. 2013;382(9904):1540-2.

4. Degenhardt L, Whiteford HA, Ferrari AJ, Baxter AJ, Charlson FJ, Hall WD, et al. Global burden of disease attributable to illicit drug use and dependence: findings from the global burden of disease study 2010 Lancet. 2013:382(9904):1564-74.

5. Drake S, Kaye S, McKetin R, Duflou J. Major physical and psychological harms of methamphetamine use. Drug and Alcohol Review. 2008;27:253-62.

6. Mokhlesi B, Garimella PS, Joffe A, Velho V. Street drug abuse leading to critical illness. Intensive Care Med. 2004;30:1526-36.

7. Nyhlen A, Fridell M, Bäckström M, Hesse M, Krantz P. Substance abuse and psychiatric co-morbidity as predictors of premature mortality in Swedish drug abusers a prospective longitudinal study 1970-2006. BMC Psychiatry. 2011;11:1-9.

8. Risdahl JM, Khanna KV, Peterson PK, Molitor TW. Opiates and infection. J Neuroimmunol. 1998;83:4-18.

9. Office of National Drug Control Policy: The economic costs of drug abuse in the United States 1992-2002. In. Washington, D.C.; 2004.

10. Harwood HJ, Fountain D, Livermore G. Cost estimates for alcohol and drug abuse. Addiction. 1999;94(5):631-47.

11. Larsson G: Bättre insatser vid missbruk och beroende: individen, kunskapen och ansvaret. In: Statens Offentliga Utredningar. Stockholm; 2011.

12. Drake RE, Bartels SJ, Teague GB, Noordsy DL, Clark RE. Treatment of substance abuse in severely mentally ill patients. J Nerv Ment Dis. 1993;181:606-11.

13. Fridell $M$, Hesse M, Jaeger-Mayer M, Kuhlhorn E. Anti-social personality disorder as a predictor of criminal behaviour in drug abusers. Addict Behav. 2008;33:799-811 
14. Grant BF, Stinson FS, Dawson DA, Chou SP, Dufour MC, Compton W, et al. Prevalence and co-occurrence of substance use disorders and independent mood and anxiety disorders: results from the national epidemiologic survey on alcohol and related conditions. Alcohol Research \& Health. 2006;29(2):107-20.

15. McGovern MP, Xie H, Saegal SR, Siembab L, Drake RE. Addiction treatment services and co-occurring disorders: prevalence estimates, treatment practices, and barriers. J Subst Abus Treat. 2006;31:267-75.

16. World Health Organization: Global status report on non-communicable diseases 2010. In. Geneva; 2011.

17. Bloom DW, Cafiero DE, Jane-Llopis E, Abrahams-Gessel S, Bloom LR, Fathima S, Feigl AB, Gaziano T, Mowafi M, Pandya A, et al. The Global Economic Burden of Non-communicable Diseases. In. Geneva; 2011.

18. Baumberg B. The global economic burden of alcohol: a review and some suggestions. Drug and Alcohol Review. 2006;25:537-51.

19. Wickizer TM. State-level estimates of the economic costs of alcohol and drug abuse. J Health Care Finance. 2013;39(3):71-84.

20. Thavorncharoensap M, Teerawattananon Y, Yothasamut J, Lertpitakpong C, Chaikledkaew U: The economic impact of alcohol consumption: a systematic review. Substance Abuse Treatment, Prevention, and Policy 2009, 4(20).

21. U.S. Department of Health and Human Services: 10th Special Report to the U.S. Congress on Alcohol and Health. In: Highlights from Current Research from the Secretary of Health and Human Services. Washington, D.C.: U.S. Department of Health and Human Services; 2000.

22. McCollister KE, French MT. The relative contribution of outcome domains in the total economic benefit of addiction interventions: a review of first findings. Addiction. 2003;98:1647-59.

23. French MT, Fang $H$, Balsa Al. Longitudinal analysis of changes in illicit drug use and health services utilization. Health Servuce Research. 2011;46(3):877-99.

24. Cherpitel CJ. Changes in substance use associated with emergency room and primary care services utilization in the United States general populaiton:1995-2000. Am J Drug Alcohol Abuse. 2003;29(4):789-802.

25. French MT, McGeary KA, Chitwood DD, McCoy CB. Chronic illicit drug use, health services utilization and the cost of medical care. Soc Sci Med. 2000;50(12):1703-13.

26. McGeary KA, French MT. Illicit drug use and emergency room utilization. Health Serv Res. 2000;35(1):153-69.

27. Ford JD, Trestman RL, Steinberg K, Tennen H, Allen S: Prospective association of anxiety, depressive, and addictive disorders with high utilization of primary, specialty and emergency medical care. Social Science \& Medicine 204, 58(11):2145-2148.

28. Rockett IRH, Putnam SL, Jia H, Chang CF, Smith GS. Unmet substance abuse treatment need, health services utilization, and cost: a population-based emergency department study. Ann Emerg Med. 2004;45(2):118-27.

29. Sterk CE, Theall KP, Elifson KW. Health care utilization among drug-using and non-drug using women. Journal of Urban Health. 2002;79(4):586-99.

30. Ottaway CA, Erickson PG. Frequent medical visits by cocaine-using subjects in a Canadian community: an invisible problem for health practitioners? J Subst Abus Treat. 1997;14(5):423-9.

31. Hoff RA, Rosenheck RA. The cost of treating substance abuse patients with and without comorbid psychiatric disorders. Psychiatr Serv. 1999;50(10):1309-15.

32. French MT, Roebuck MC, Dennis ML, Godley SH, Liddle H, Tims FM. Outpatient marijuana treatment for adolescents: economic evaluation of a multisite field experiment. Eval Rev. 2003;27(4):421-59.

33. French MT, Roebuck MC, Dennis ML, Diamond G, Godley S, Tims F, et al. The economic cost of out-patient marijuana treatment for adolescents: findings from a multisite field experiment. Addiction. 2002;97:84-97.

34. French MT, McCollister KE, Cacciola J, Durell J, Stephens RL. Benefit-cost analysis of addiction treatment in Arkansas: specialty and standard residential programs for pregnant and parenting women. Subst Abus. 2002:23:31-51

35. Wagner $\mathrm{TH}, \mathrm{Chen} \mathrm{S}$. An economic evaluation of inpatient residential treatment programs in the Department of Veterans Affairs. Med Care Res Rev. 2005;62(2):187-204.

36. Siegal HA, Falck RS, Wang J, Carlson RG, Massimino KP. Emergency department utilization by crack-cocaine smokers in Dayton, Ohio. The American Journal of Drug and Alcohol Abuse. 2006;32:55-68.

37. Santora PB, Hutton HE. Longitudinal trends in hospital admissions with co-occurring alcohol/drug diagnoses, 1994-2002. Journal of Substace Abuse Treatment. 2008;35:1-12

38. French MT, Drummond M. A research agenda for economic evaluation of substance abuse services. Journal of Substace Abuse Treatment. 2005;29:125-37.
39. Olsson TM. Economic evaluation as a component of quality effectiveness research: Practical and methodological benefits. Child and Youth Care Forum. 2012;41(2):137-48.

40. Fridell M, Billsten J, Jansson I, Amylon R. Femårsuppföljning av kvinnor vårdade vid Lundens ungdomshem och LVM-hem. In: SiS följer upp och utvecklar 1/09. Stockholm: Statens institutionsstyrelse; 2009.

41. Jansson I. Femårsuppföljning av tvångsvårdade kvinnor: inverkan av psykiska problem på utfallet. Lund, Sweden: Lund University; 2010.

42. Nilsson M, Fridell M, Griffiths P: Comorbidity - Developing a European perspective. In: ECCAS: Monograph Series. vol. 4: Comorbidity in Europe. Lisboa; 2006: 351-363.

43. Drake RE. Dual diagnosis. Psychiatry. 2007;6:381-4.

44. Olsson TM, Fridell M. Women with co-occurring substance abuse and mental disorders in Sweden: A longitudinal study of criminal justice system involvement and costs. Mental Health and Substance Use. 2013;6(3):17.

45. Olsson TM: Productivity loss, victim costs and the intangible costs of crime: Follow-up to a longitudinal study of criminal justice system involvement and costs of women with co-occurring substance abuse and mental disorders in Sweden. Mental Health and Substance Use 2013.

46. Jansson I, Hesse M, Fridell M. Validity of self-reporting criminal justice system involvement in substance abusing women at five-year follow-up. BMC Psychiatry. 2008:8:8-10.

47. Jansson I, Hesse M, Fridell M. Personality disorder features as predictors of symptoms five years post-treatment. Am J Addict. 2008;17:172-5.

48. Jansson I, Hesse M, Fridell M. Influence of personality disorder features on social functioning in substance-abusing women five years after compulsive residential treatment. Eur Addict Res. 2009;15:25-31.

49. Allgulander C. DSM-III-R personlighetsstörningsformulär för SCID-II. Stockholm, Sweden: Karolinska Institutet; 1988.

50. Öhlin L, Fridell M, Nyhlen A: Buprenorphine maintenance program with contracted work/education and low tolerance for non-prescribed drug use: a cohort study of outcome for women and men after seven years. BMC Psychiatry 2014, in press.

51. National Board of Institutional Care: Research projects from SiS. In Stockholm; 2011.

52. National Board of Health and Welfare: Classification of illnesses 1987 systematic index. In. Stockholm; n.d.a.

53. National Board of Health and Welfare: Classification of illnesses 1968 systematic index (ICD-8). In. Stockholm; n.d.b.

54. National Board of Health and Welfare: International statistical classification of illnesses and related health problems - systematic index (ICD-10-SE). In Stockholm; 2010.

55. KPP (kostnad per patient) database. Average unit cost per day by main diagnosis, 2010, all cases [skl.se/ekonomijuridikstatistik/ statistiknyckeltaljamforelser/kostnadperpatientkpp/databaskpp/1079.html]

56. KPP (kostand per patient) database. Average unit cost per day by main diagnosis 2010, women. [http://stat2.skl.se/kpp/index.htm]

57. Drummond MF. McGuire A: Economic evaluation in health care: merging theory with practice. Oxford: Oxford University Press; 2001.

58. Mattke S, Balakrishnan A, Bergamo G, Newberry SJ. A review of methods to measure health-related productivity loss. The American Journal of Managed Care. 2007;13:211-8.

59. Zhang W, Bansback N, Anis AH. Measuring and valuing productivity loss due to poor health: A critical review. Soc Sci Med. 2011;72:185-92.

60. Genomsnittlig grund- och månadslön samt kvinnors lön i procent av mäns lön efter sektor, yrke (SSYK), kön och ålder. År 2005-2011 [Average base and monthly salaries and women's salary as a percentage of men's salary after field and position, gender, and age, years 2005-2011] [http://www.ssd scb.se/databaser/makro/Visavar.asp?yp=tansss\&xu=C9233001\&omradekod= AM\&huvudtabell=LonYrkeAlder4\&omradetext=Arbetsmarknad\&tabelltext= Genomsnittlig+grund\%2D+och+m\%E5nadsl\%F6n+samt+kvinnors+l\%F6n+i +procent+av+m\%E4ns+1\%F6n+efter+sektor\%2C+yrke+\%28SSYK\%29\%2C + +k\%Fn+och+\%E5lder\%2E+\%C5r\&preskat=O\&prodid=AM0110\&deltabell= \&deltabellnamn=Genomsnittlig+grund\%2D+och+m\%E5nadsl\%F6n+samt + kvinnors+l\%F6n+i+procent+av+m\%E4ns+l\%F6n+efter+sektor\%2C+yrke +\%28SSYK\%29\%2C+k\%F6n+och+\%E5Ider\%2E+\%C5r\&innehall=Antal\&start]

61. OECD StatExtracts. PPPs and exchange rates. 2012. [https://stats.oecd.org/ Index.aspx?datasetcode=SNA TABLE4]

62. Swedish Association of Local Authorities and Regions: Öppna jämförelser av hälso- och sjukvårdens kvalitet och effektivitet 2011. Bilaga 3

Vårdkonsumtion - jämförelser mellan landsting. 2011.

63. Kelly TM, Daley DC, Douaihy AB. Treatment of substance abusing patients with comorbid psychiatric disorders. Addict Behav. 2012;37:11-24. 
64. Swedish Association of Local Authorities and Regions: Öppna jämförelser av hälso- och sjukvårdens kvalitet och effektivitet - jämförelser mellan landsting 2011. In. Stockholm; 2011.

65. Berglund $\mathrm{M}$, Thelander S, Jonsson E. Treatment of alcohol and drug abuse. Evidence-based review. Darmstadt: Wiley, VCH Gmbh \& Co KGaA; 2003.

66. Olsson TM, Ferrer-Wreder L, Eninger L: Advancing school-based interventions through economic evaluation. New Directions for Youth Development 2014, in press.

67. Stenbacka M, Leifman A, Romelsjö A. Mortality and cause of death among 1705 illicit drug users: a 37 year follow-up. Drug and Alcohol Review. 2010;29:21-7.

68. Swedish Association of Local Authorities and Regions: Kostnad per vårdtillfälle, vårddag och läkarbesök på sjukhus 2001. 2003.

69. National Board of Health and Welfare: Hälso- och sjukvårdsrapport - 2009. In Stockholm; 2009.

70. National Board of Health and Welfare: Folkhälsorapport 2009. In. Stockholm; 2009

71. National Board of Health and Welfare: Öppna jämförelser och utvärdering 2010 - Psykiatrisk vård. In. Stockholm; 2010.

72. National Board of Health and Welfare: Jämställd vård? Könsperspektiv på hälso- och sjukvården. In. Stockholm: National Board of Health and Welfare; 2004.

73. Clark RE, Drake RE. Expenditures of time and money by families of people with severe mental illness and substance use disorders. Community Ment Health J. 1994;30:145-63.

74. Lohrer SP, Lukens EP, Thorning H. Economic expenditures associated with instumental caregiving roles of adult siblings of persons with severe mental illness. Community Ment Health J. 2007;43:129-51.

\section{Submit your next manuscript to BioMed Central and take full advantage of:}

- Convenient online submission

- Thorough peer review

- No space constraints or color figure charges

- Immediate publication on acceptance

- Inclusion in PubMed, CAS, Scopus and Google Scholar

- Research which is freely available for redistribution 